\title{
الديناميات الساحليّة واستراتيجيات التببير الساحليّ بساحل مدينة العيون بالصحراء المغربيّة
}

\section{Coastal Dynamics and the strategies of the Coastal Management in the coast of Laayoune city in the Moroccan Desert}

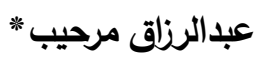

يعد موضوع الساحل وآثار التذخل البشري على منظومته البيئية إحدى أهم التوجهات العالمية في مختلف المحافل الدولية والمؤتمرات البيئية، وقد حضيت المجالات الساحليّة باهتمام بالغ من مختلف العلماء والباحثين والفاعلين، نتيجة اختلال التوازن الطبيعي سواء بالمجال القاري أو الساحلي الذي أصبح يهدد المنظومة البيئية.

ويشَّل ساحل إقليم العيون وسطًا هشَّا ناتجًا في الأساس عن تظافر عوامل طبيعية وبشرية، فالمجال الساحلي هو نظام قائم على التبادلات بين المجال القاريّ والمجال البحريّ، وهذا ما يجعله حساسًا، وعرضة للخطر جرّاء أيّ تدخل بشري غير معقلن.

ولقد قمنا بهذه الدراسة قصد التعريف بهذا الوسط الساحلي الصحراوي، المتمثل في ساحل إقليم العيون، للشريط الساحلي الواقع بين مصب واد الساقية الحمراء ومركز المرسى. فالتطور المرفولوجي لخط الساحل بمجال دراستتا ترجع أسبابه إلى التّخلات البشرية، التي تعدّ من بين العوامل الرئيسية المسؤولة عن الاختلالات التي يشهدها هذا المجال، إضافة إلى العوامل الطبيعية المتمثلة في العوامل الهيدرودينامية. فالتدخلات التي لم تراع الخصوصيات الطبيعية للمنظومة الساحلية أدت إلى هذه الاختلالات السابقة الذكر وفي ظل كل هذه الاختلالات نلاحظ القصور الكبير الذي يطال التدبير الساحلي بإقليم العيون، بحيث أن كل هذه التدخلات تبقى ضعيفة جدًا، ولا تعتمد إلا على المقاربة القطاعية التي هي بعيدة كل البعد عن التدبير المندمج للمجالات الساحلية، والتي ستزيد لا محالة من تدهور هذا الوسط الساحلي. والإشكالية المراد معالجتها في هذه الدراسة تتحدد انطلاقًا من دراسة الديناميات المتحكمة في التطور الجيومرفلوجي للشريط الساحلي بإقليم العيون، وسنعالج هذه الإثكالية عن طريق دراسة الديناميات الطبيعية المرتبطة بالهيدرودينامية الساحلية من جهة، ثم سنحاول ضبط التدخلات البشرية التي تساهم في تطور خط الساحل.

الكلمات المفتاحيّة: الساحل، مدينة العيون، الدينامية الساحليّة، التدبير الساحليّ، الهيدرودينامية الساحليّة. 


\begin{abstract}
The topic of the coastal and the effects of human intervention on its ecosystem is one of the most important tendencies worldwide in various international forums and environmental conferences. The coastal zones have received much attention by various scientists, researchers as well as of activists, following the natural imbalance on both the continental and coastal zones alike, which has posed threats against its ecosystem. The coastal of the region of Laayoune is a fragile intermediate space, owing, in the first place, to the combination of natural and human factors. The coastal zone is a system based on exchanges between the continental and maritime sphere, what makes it sensitive and vulnerable due to any human irrational intervention. We conducted this study in order to introduce this desert coastal center, represented by the coast of the region of Laayoune, of the coastal strip located between Assakia El Hamra valey and the center of Al-marsa.

The morphological evolution of the coastal in our space of study is attriburted to the human interventions, which head the main responsible factors for the imbalances in this space together with to the natural factors represented by hydrodynamics. Interventions that did not take into account the natural peculiarities of the coastal system led to these aforementioned imbalances.In light of all these imbalances, we note the great shortcomings that affect coastal management in the region of Laayoune where all these interventions remain very weak and only rely on sectorial approximation, which is very far from the management integrated with the coastal zones, which will inevitably worsen the deterioration the coastal environment.

The problem to be addressed in this study is determined from the study of the dynamics controlling the geomorphological development of the coastal strip in the region of Laayoune. We will address this problem by studying the natural dynamics associated with coastal hydrodynamics on the one hand, and then we will try to control human interventions that contribute to the development of the coastline.

Key Words: The Coast, Laàyoune City, Coastal Dynamics, Coastal Management, Coastal Hydrodynamics
\end{abstract}

\title{
المقدمة
}

يشهُ ساحل العيون شأنه شأن باقي سواحل العالم تحولات مستمرة على مستوى تطور خط الساحل، يتمثل في التراجع أو التقدم لخط الساحل بفعل الديناميات التي تتدخل في تشكيل هذا التطور على مستوى خط الساحل، ويشكل

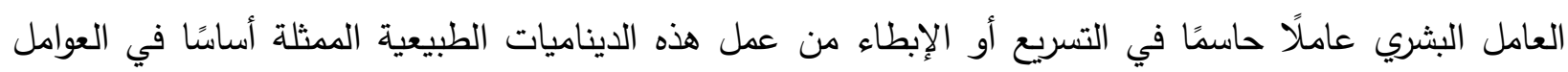
الهيدرودينامية.

ويفتقر هذا الثربط الساحلي قيد الدراسة من حيث الدراسات والأبحاث الساحلية كجُلّ الأقاليم الجنوبية، على الرغم من كونه يشكل موقعًا استراتيجيًا لكل مشاريع التتمية بما فيها الأنشطة السياحية والاقتصادية، وذلك لارتباطه بإقليم العيون باعتباره أكبر المدن والعاصمة الاقتصادية للأقاليم الجنوبية.

ومن هذا المنطلق فقد أضحى تدبير المجالات الساحلية ضرورة حتمية لضمان استقرار التوازن البيئي وتحقيق تتمية مستدامة في مجالات هشة تستدعي مراعاة خصائصها الطبيعية.

إشكالية البحث

$$
\begin{aligned}
& \text { يعد ساحل مدينة العيون من المجالات الساحلية التي استقبلت مشاريع تتموية شتى (صناعية، سياحية...) } \\
& \text { منذ القرن الماضي، ولا زالت المدينة تُعد قبلة لمشاريع تتموية متعددة ليومنا هذا. }
\end{aligned}
$$


والإثكالية المراد معالجتها في هذا البحث تتحدد انطلاقًا من دراسة الديناميات المتحكمة في التطور الجيومرفلوجي للشريط الساحلي بمدينة العيون، وسنعالج هذه الإشكالية عن طريق دراسة الديناميات الطبيعية سواء المرتبطة

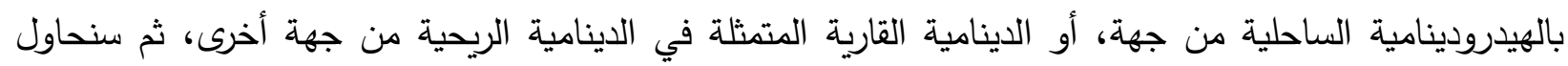
ضبط التتخلات البشرية التي تساهم في تطور خط الساحل.

إذن؛ ما مدى تأثير الديناميات الطبيعية المتحكمة في تطور مرفولوجية الثريط الساحلي بمدينة العيون؟ وماهي التطورات التي عرفها خط الساحل بمجال دراستنا؟ وما مدى مساهمة وتأثير العامل البشري في هذا التطور؟ ويمكن صياغة هذه الإشكالية العامة إلى عدة تساؤلات فرعية :

- ما خصوصيات المجال المدروس من الناحية الطبيعية ؟ - ما الخصوصيات الطبيعية لحوض الساقية الحمراء، وما مدى تأثيره على ساحل مدينة العيون ؟ - كيف تطور خط الساحل خلال العقود الأخيرة، وما مدى تأثير العامل البشري في هذا التطور ؟ - كيف تؤثر الديناميات الطبيعية والبشرية في تدهور هذا المجال الساحلي ؟ - كيف يتم تدبير المجال المدروس والحفاظ على توازنه واستدامة موارده، في خضم الأنشطة البشرية والديناميات

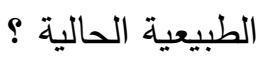

\section{منهجية الدراسة}

قمنا في دراستنا لساحل إقليم العيون بالاعتماد على المقاربة التاريخية، وذلك بالاعتماد على نظم المعلومات الجغرافية، وتحديدًا برنامج ARC GIS 10.4.1، بحيث قمنا بتتبع مراحل تطور خط الساحل بالاعتماد على صور الأقمار الاصطناعية LANDSAT للسنوات 1984، 1994، 2005، 2016، للمجال الساحلي الواقع ما بين

$$
\text { مصب فم الواد وميناء مدينة العيون. }
$$

تُُعد صورة القمر الاصطناعي أفضل وسيلة وأحدثها لدراسة تطور خط الساحل، ومن أجل الحصول على نتائج دقيقة قمنا بتثبيت هذه الصور بواسطة برنامج ARC GIS 10.4.1، وقد اعتمدنا على نظام الإحداثيات الخرائطي

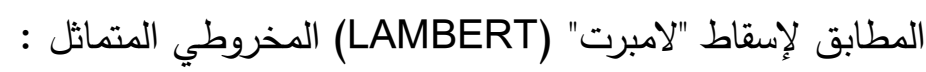
- SUD MAROC . PROJECTION : LAMBERT_CONFORNAL_CONIC.

سنقوم في هذه الدراسة بالتعرف على التطور الذي عرفه خط الساحل لإقليم العيون، بحيث سنقوم بتتبع مراحل تطور خط الساحل بالاعتماد على صور الأقمار الاصطناعية للسنوات 1984، 1994، 2005، 2016؛ للمجال الساحلي الواقع ما بين مصب فم الواد وميناء مدينة العيون.

وسنقوم كذلك بالتعرف على العوامل الهيدرودينامية المسؤولة عن هذا التطور الحاصل على المستوى المرفولوجي لخط ساحل، وكذا التعرف على الأشكال المورفولوجية الحاصلة عن هذه العوامل التي تميز مجال دراستنا. 


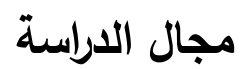

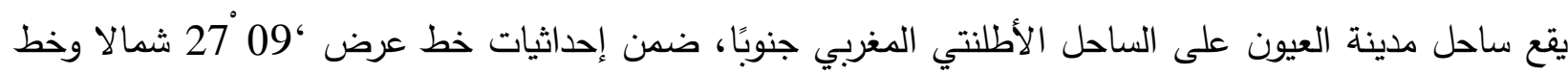

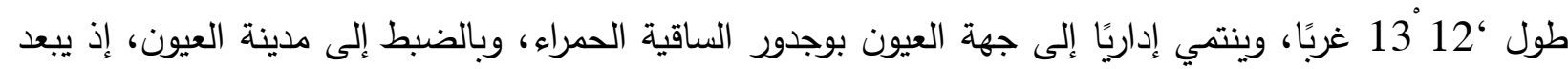

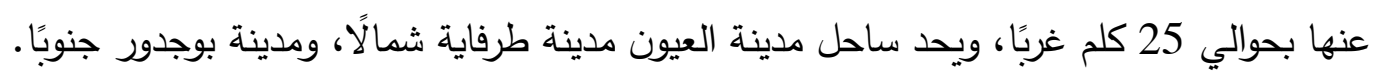

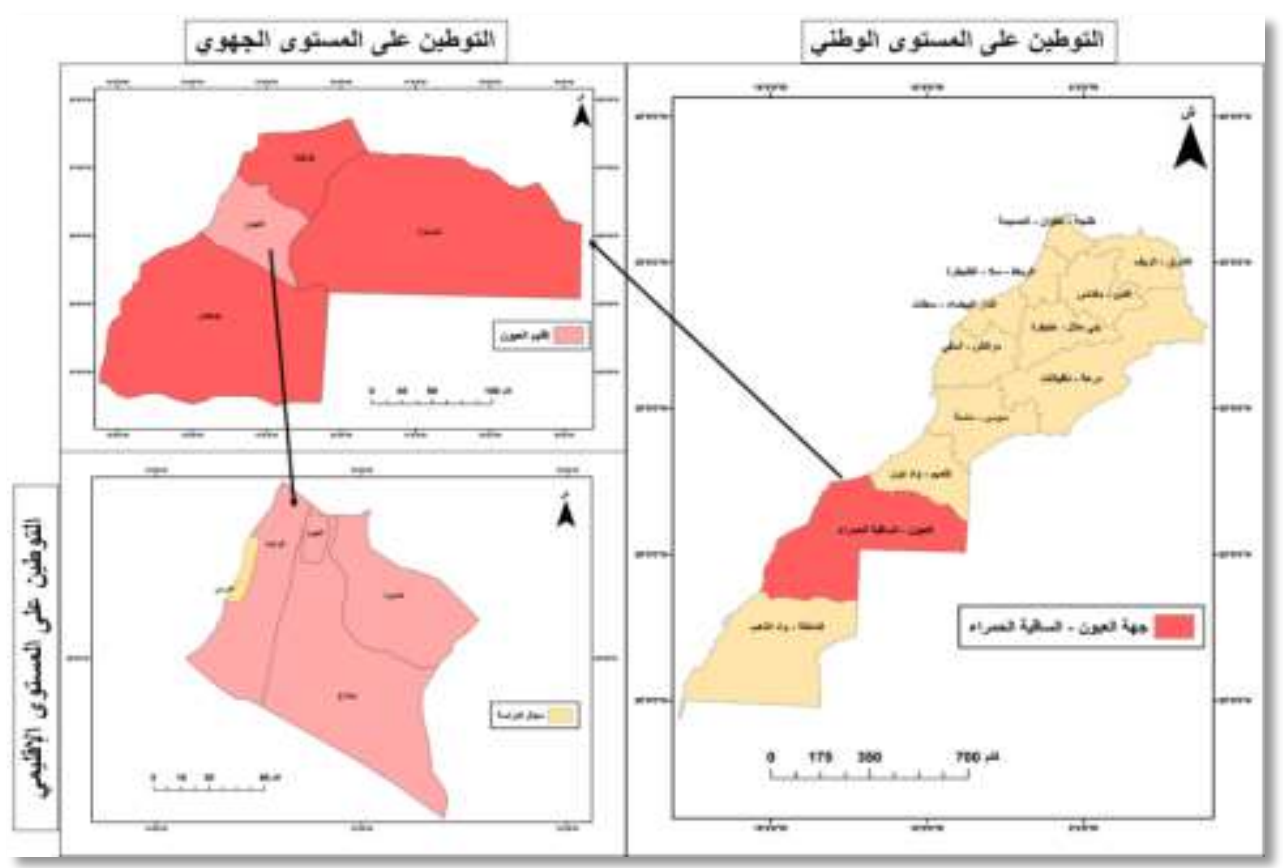

الخريطة رقم 1 : موقع ساحل مدينة العيون على الساحل الأطلنتي

1.4

مجال دراستا يتميز بهضاب شاسعة ووعرة، وتعدّ هذه الهضاب أهم شكل تضاريسي يميز الإقليم، أهمها

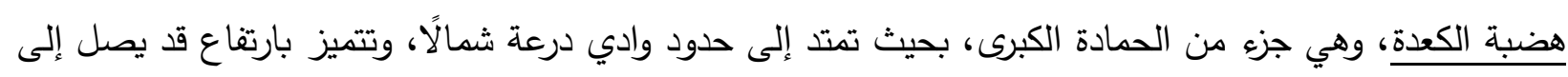
300

والكعدة عبارة عن هضاب كلسية، يقطعها وادي الساقية الحمراء بثكل مستعرض وعميق، مما يجلها تطل

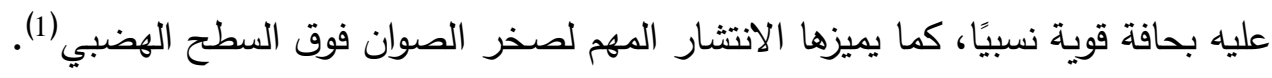
السهل الساحلي :يُعد جزءًا من السهل الممتد من طرفاية إلى حدود موريتانيا، ويبدأ من نهاية هضبة الكعدة إلى المحيط الأطلنتي. الأودية الرملية : منطلقها الساحل المتد بين أخفنير وطرفاية في الثمال، مرورًا بمدينة العيون نحو

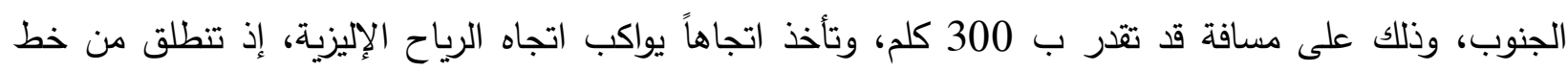

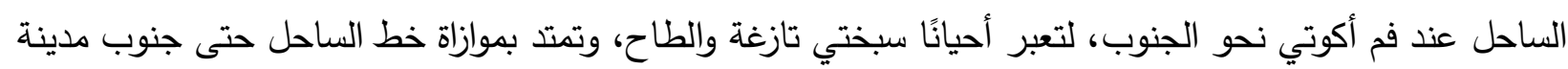

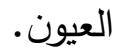




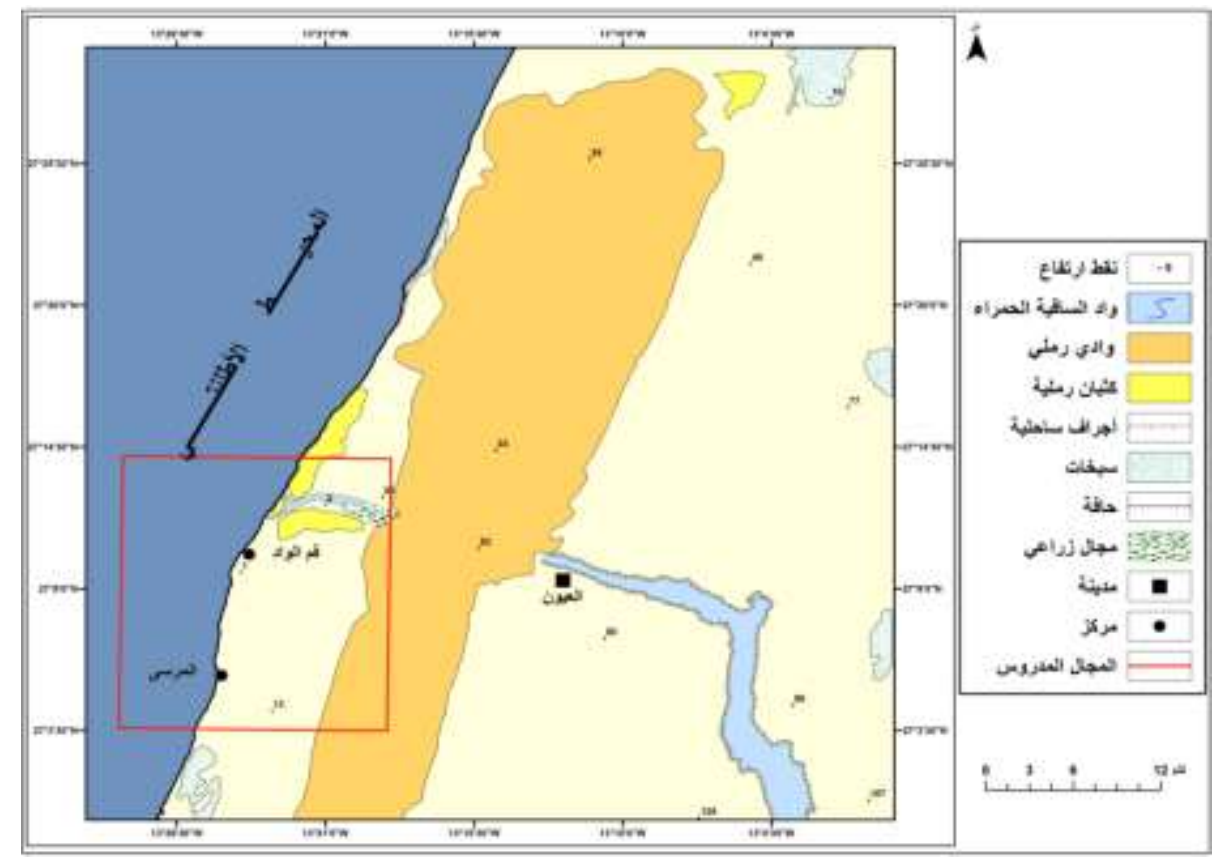

الخريطة رقم 2 : طبوغرافية مجال مدينة العيون

2.4 - جيولوجيا

من خلال الخريطة الجيولوجية لإقليم العيون، يمكن أن نوزع البنيات الجيولوجية المشكلة للإقليم إلى ثلاث وحدات :

- الوحدة الأولى : تغطي مساحة صغيرة نوعًا ما، وتتموضع في أقصى الجنوب الثرقي للإقليم، وهي تعود إلى الزمن الجيولوجي الأول، وما قبل الكمبري تتكون أساسًا من صخور متحولة وصخور متبلورة. - الوحدة الثانية: من الناحية المجالية تمتد على شكل شريط طولي، يقطع الإقليم عموديًا من الثمال الشرقي إلى جنوب الإقليم، توضعات هذه الوحدة تعود إلى الزمن الثاني خاصة الكريطاسي. - الوحدة الثالثة: تغطي الشريط الساحلي الطولي الذي يمتد من الثمال الشرقي إلى الجنوب الغربي، ومكوناتها تعود إلى الزمن الثالث وأخرى للزمن الرابع. بالنسبة للأولى فهي تتكون من الميوسين، وهو أساسًا صلصالي، أما بالنسبة

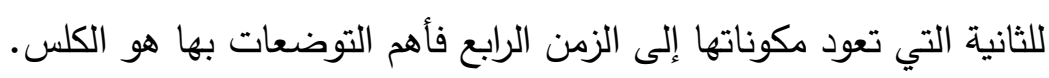




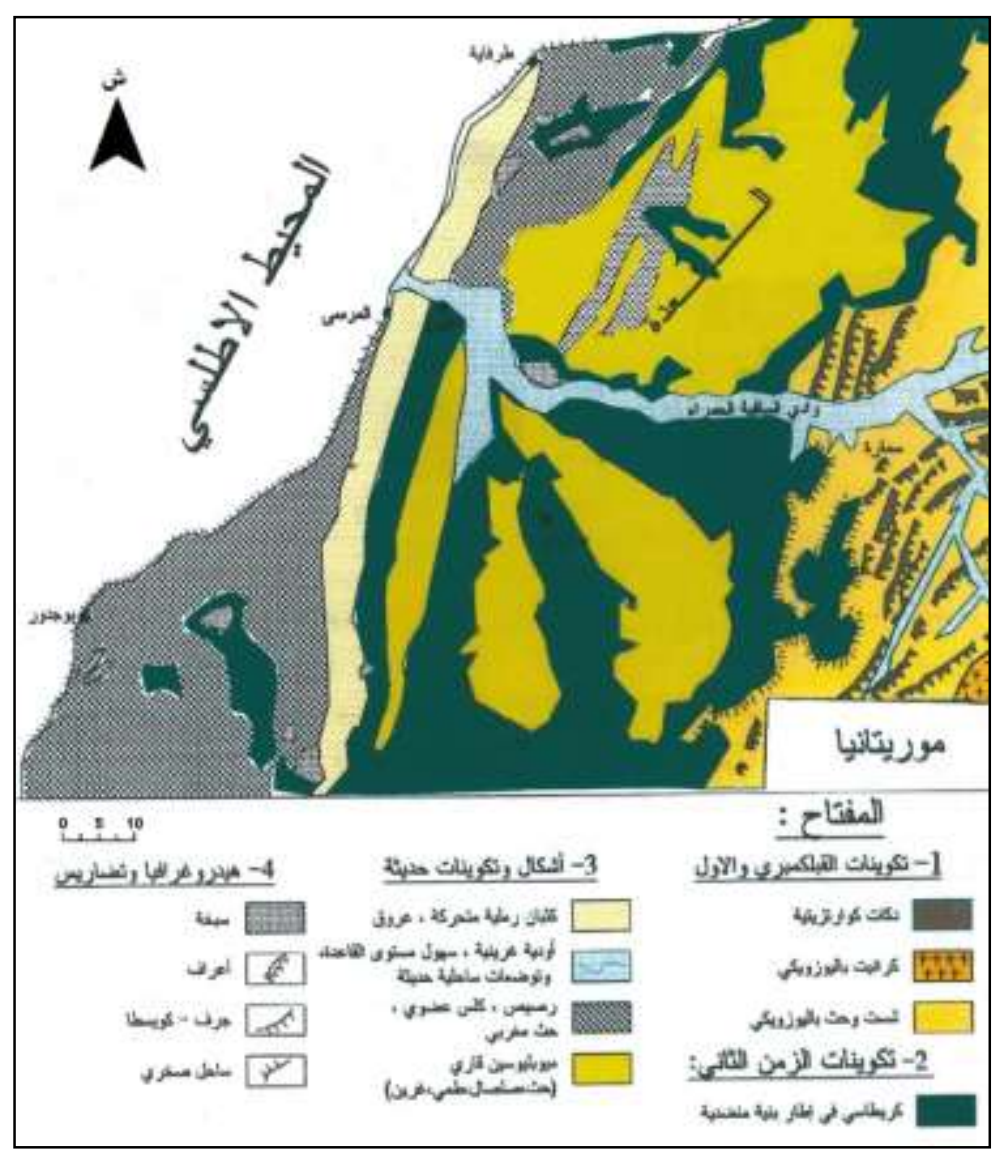

الخريطة رقم 3 : جيولوجيا مجال مدينة العيون

: 3.4

- ينتمي مجال دراستنا لمصب حوض الساقية الحمراء بالساحل الأطلنتي، ويعد حوض الساقية الحمراء عنصرًا مؤثرًا على طول مجال دراستنا؛ وذلك عن طريق الحمولة الرسابية التي تصل إلى الساحل خلال فترة الفيضانات. ويُعُُ حوض الساقية الحمراء الحوض الرئيسي من الجهات الجنوبية المغربية، ويرجع ذلك لمساحته الكبيرة التي تقدر ب 81000 كلم²، ويمتد على طول 400 كلم، إذ إن روافده تتطلق من أقصى المناطق الصحراوية الشرقية عند كتلة الركيبات، وعند زمور الكحل (2). أ - الارتفاعات :

يتميز حوض الساقية الحمراء بارتفاعات تتراوح ما بين 426م و618م عند عاليته، وبالتحديد عند منطقة زمور الكحل الصحراوية شرقًا، بحيث تتوزع هاته الارتقاعات شرقاً وشمال شرق الحوض عند منطقة البير لحلو، ومن الجنوب الشرقي للحوض عند منطقة الفارسية، وينتهي الحوض بمصب "فم الواد" غربًا عند المحيط الأطلنتي، بحيث تتراوح الارتفاعات بهذا المجال ما بين -24ح و 172م. 


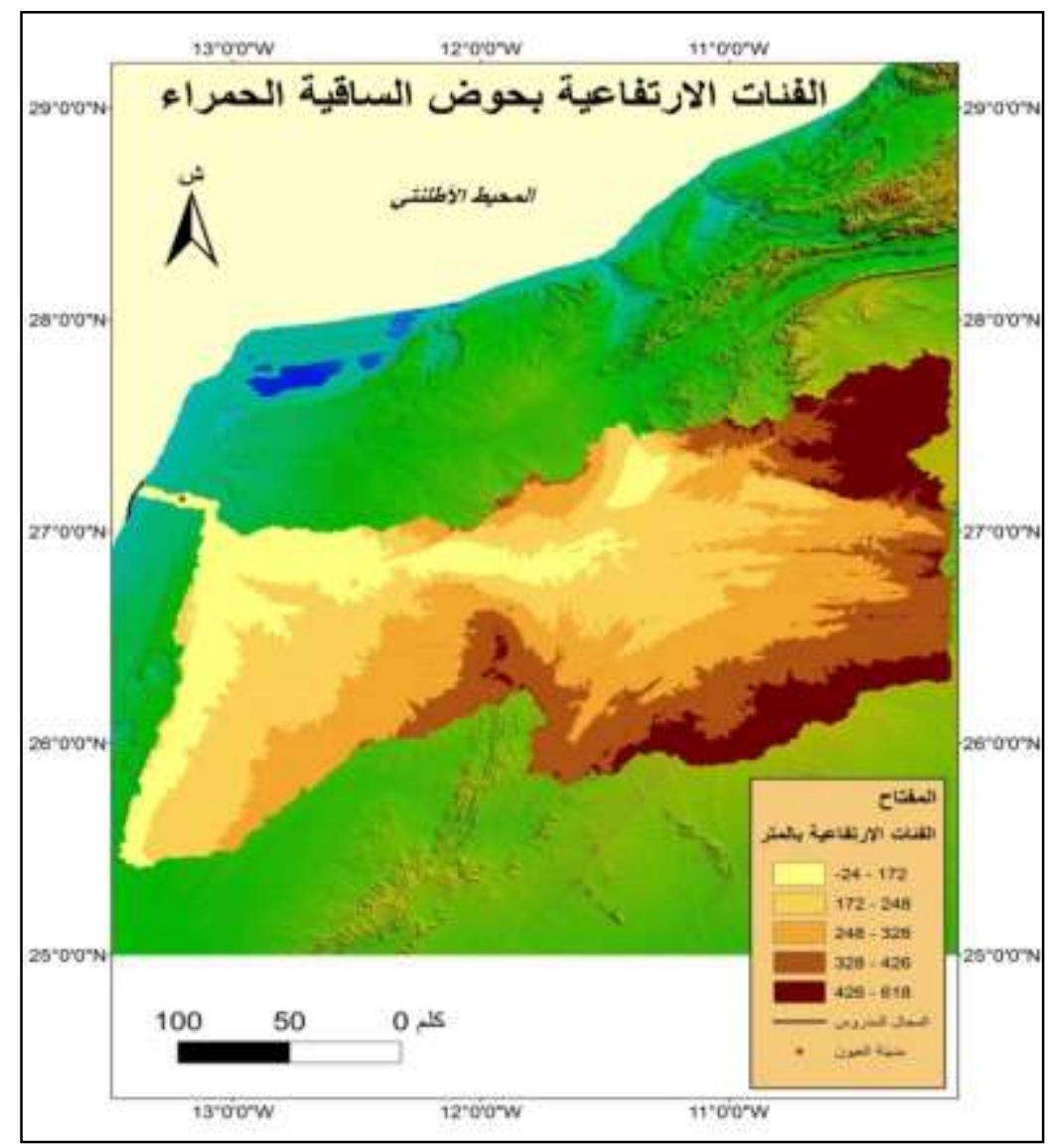

الخريطة رقم 4 : الفئات الارتفاعية بحوض الساقية الحمراء

ب - الشبكة المائية بحوض الساقية الحمراء :

إن الأحواض النهرية في الدجالات الصحراوية تتسم بالكثافة؛ ارتباطًا بطبيعة طبوغرافية السطح وخصائص

$$
\text { المناخ المحلي، بالإضافة لدور الغطاء النباتي في تثكيل السيل. }
$$

ويشكل وادي الساقية الحمراء المجرى الرئيسي لحوض الساقية الحمراء، ويتخذ مجراه من الشرق نحو الغرب، ويرتبط مستوى تغذيته بكمية التساقطات الموسمية.

ويتميز حوض الساقية الحمراء بشبكة مائية كثيفة، مع سيادة المجاري المائية الموسمية التي تتمثل في مجموعة من المسيلات المتفرعة. 


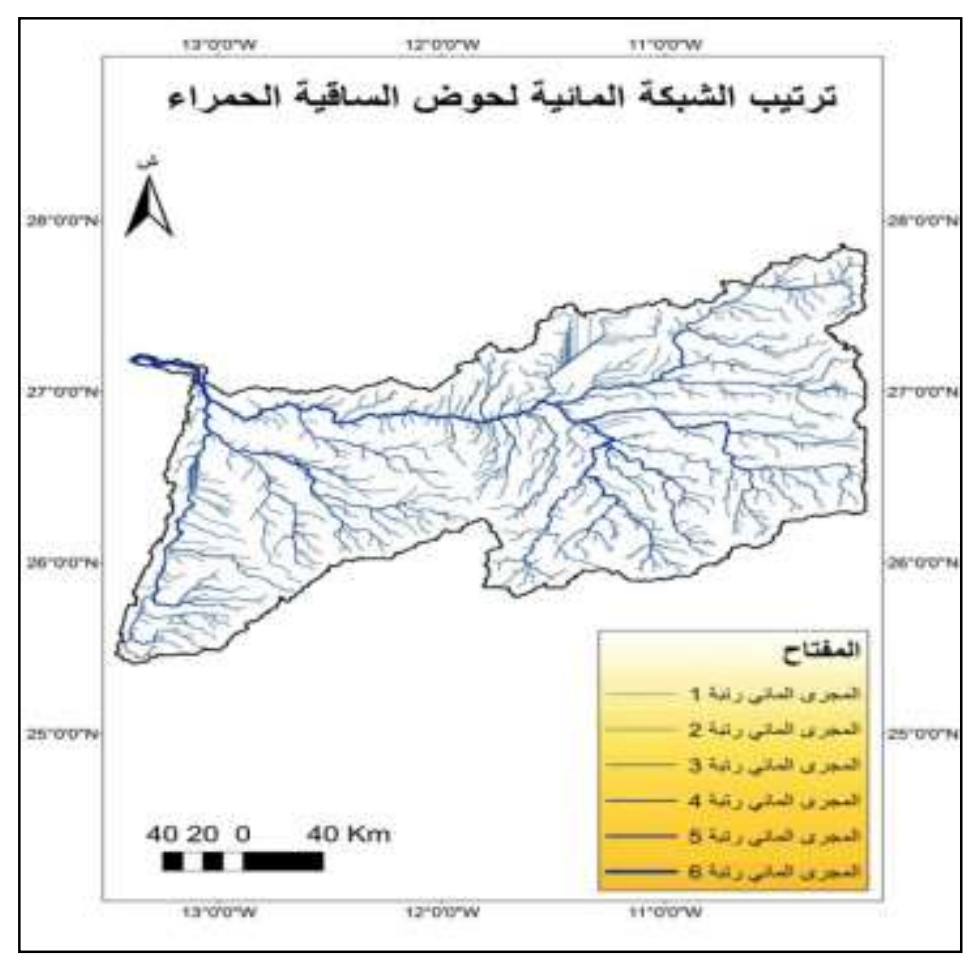

الخريطة رقم 5 : الشبكة المائية لحوض الساقية الحمراء

$$
\text { : } 4.4
$$

يدخل إقليم العيون ضمن مجال صحراوي يسود فيه مناخ جاف، تزداد قحولته كلما ابتعدنا عن المحيط، حيث إن التأثيرات البحرية تتحصر فقط على الثريط الساحلي التي لا تتجاوز 50 كلم نحو الداخل(3). وإلى جانب قلة التساقطات وعدم انتظامها وتأثرها بالاضطرابات الجوية للمحيط الأطلنتي؛ نجد الرياح تتميز بقوتها وغلبة طابع الزوابع الرملية بها.

فالحرارة في إقليم العيون تتميز نسبيًا بالاعتدال، وترتقع كلما اتجهنا نحو الداخل، كما أن الحرارة المتوسطة المسجلة خلال مدة 23 سنة (ما بين 1993 إلى 2016) لا تتعدى 21.3، حتى المعدلات القصوى حددت في 27.36، بينما المعدلات الدنيا نزلت إلى 15.29. أما التساقطات المطرية فإنها تتأثر بالتقلبات الجوية للمحيط الأطلنتي، وهي قليلة جدًا، ولا تتجاوز 60 ملم في السنة بإقليم العيون. كما أن التساقطات لا تستمر إلا لمدة قصيرة، وهي غير منتظمة وعاصفية خاصة في الصيف(4). 


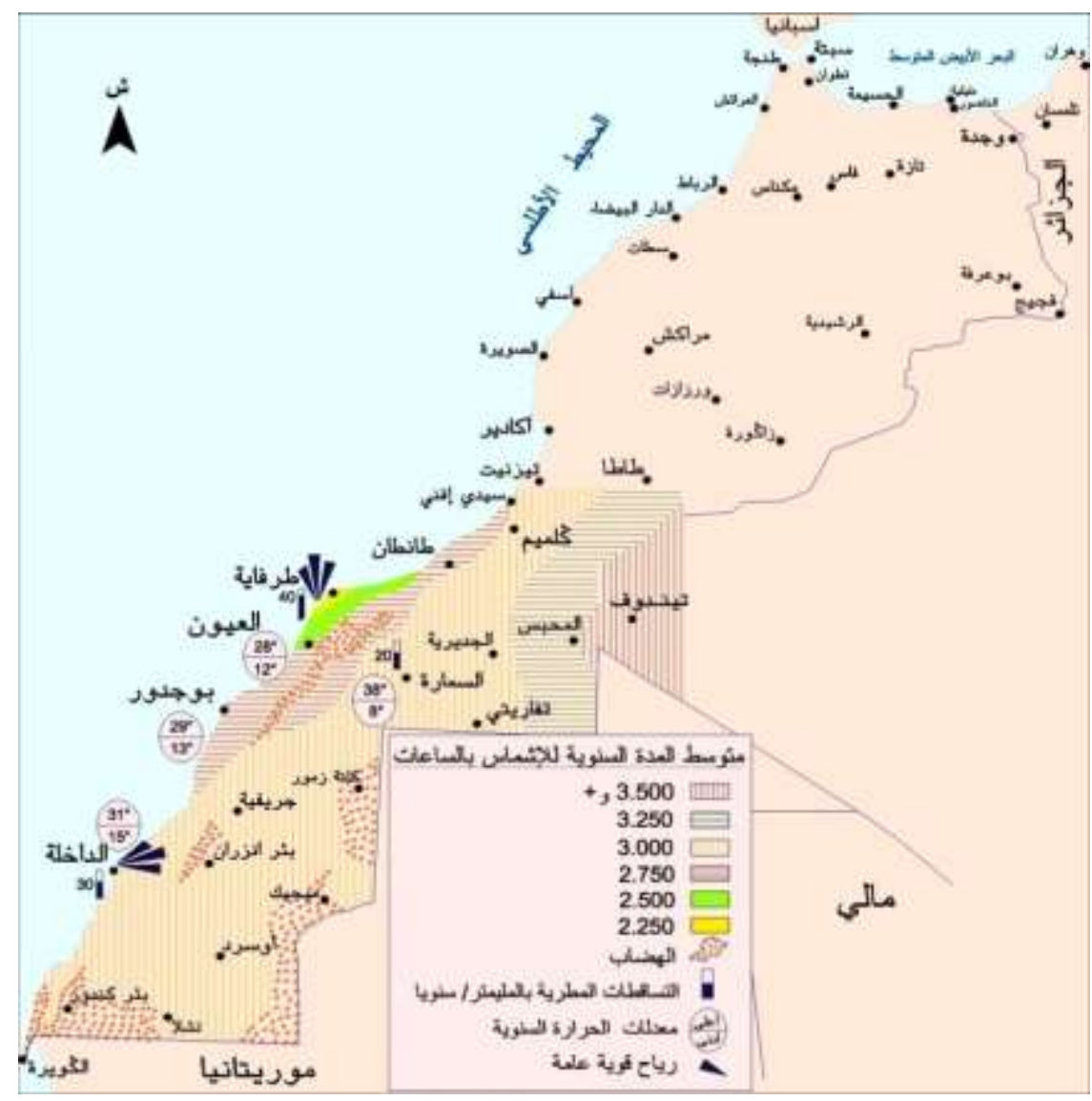

الخريطة رقم 6 : المناخ بالصحراء المغربية

\section{5 - التطور المرفولوجي لمدينة العيون وإنعكاسه على المجال الساحلي:}

إن السبب الرئيسي وراء بداية الاستقرار البشري الفعلي بمدينة العيون ارتبط بعيون الماء التي كانت منتشرة على ضفاف واد الساقية الحمراء، لهذا السبب تمركزت المدينة وتوسعت على الضفة اليسرى للواد، ويمكن العودة بالبداية الفعلية للاستقرار البشري إلى سنة 1960 التي شهدت بعدها المدينة توسعًا حضريًا أكثر تسارعًا، ففي هذه السنة ظهرت أولى الأحياء السكنية في المدينة، ومن بين هذه الأحياء سوق الجمال ودريدك والحي الحسني وغيرهم، وأغلب هذه الأحياء تمركزت مباشرة على ضفة الواد. 


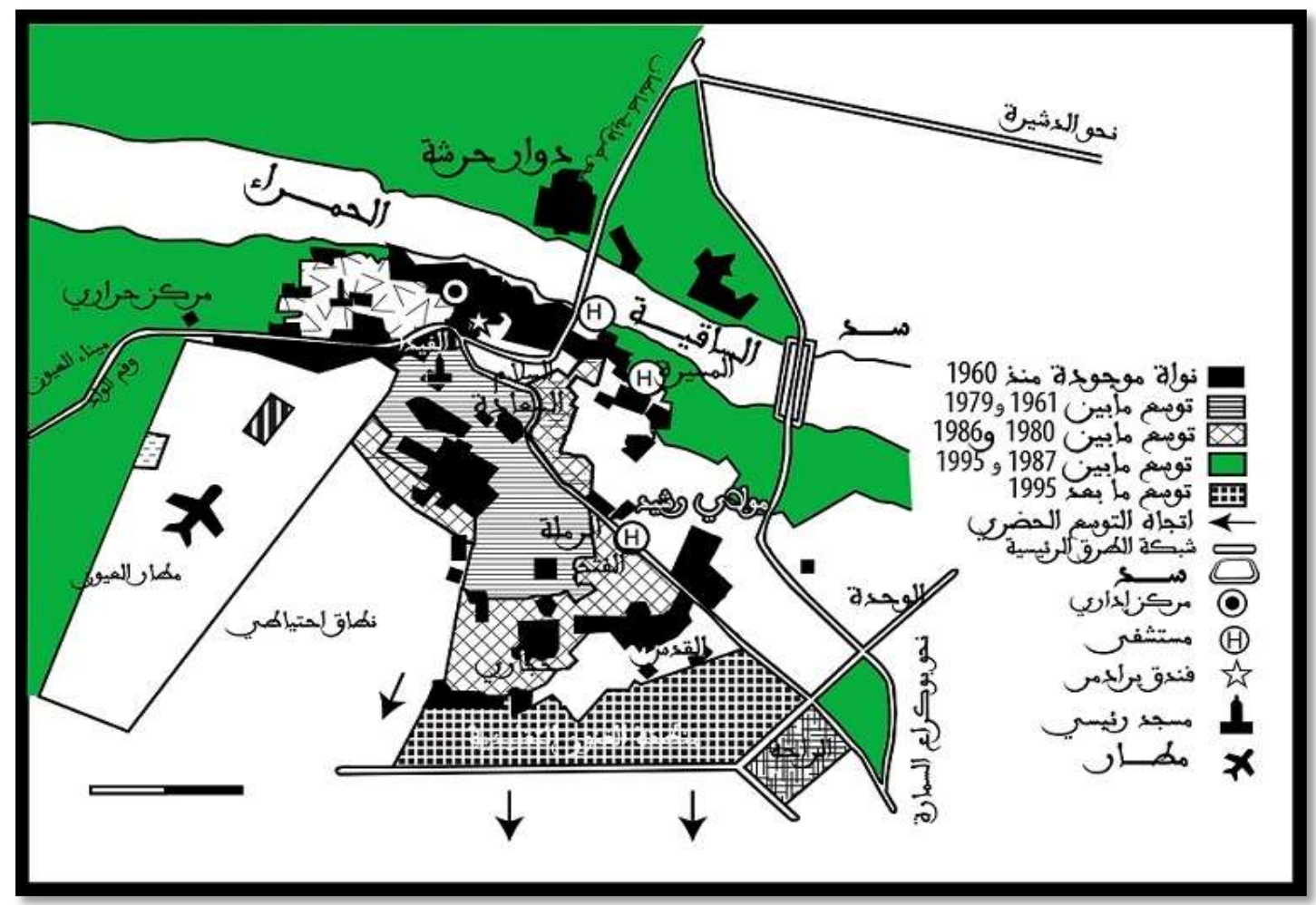

الخريطة رقم 7 : التطور المرفولوجي لمدينة العيون(5)

وبعد مرور عقدين من الزمن نجد أن المدينة اتسعت بشكل كبير ، بحيث ظهرت أحياء جديدة، كالحي الإسماعيلي وحي المطار وحي السعادة وحي التعاون وغيرهم، بالإضافة إلى التوسع الذي شهدته الأحياء القديمة، وهذا راجع إلى الاستقرار الكبير الذي عرفته المدينة، خاصة بعد خروج الاستعمار سنة 1975، حيث اعتمدت الدولة على قطاع البناء بشكل كبير ، وهذا ما جعل نسبة مهمة من ساكنة المدينة تستقيد من السكن الممنوح أو السكن الوظيفي. وفي الفترة ما بين 1980 - 1986 فقد ظهرت بوادر اتساع المدينة الكبير في اتجاه الشرق والجنوب الشرقي، وهذا راجع إلى صعوبة التوسع الحضري شمالًا بواد الساقية الحمراء وفي اتجاه غرب المطار والحزام الرملي، وقد وصل اتساع المدينة إلى أقصاه في الفترة ما بين 1987 - 1995 وما بعد سنة 1995، حيث ظهرت أحياء جديدة شرق المدينة وجنوبها وغربها، أهمها حي الفتح وحي القدس ومخيم الوحدة، ولم يقتصر الأمر على هذا فحسب، بل تم خلق مدن جديدة، وما زالت المدينة تنمو نموًا ديموغرافيًا كبيرًا وسريعًا، وتوفرها على احتياط عقاري مهم، ساعدها على تحقيق التوسع الحالي (6).

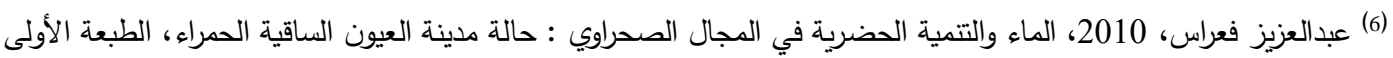




\section{5}

يقصد بالتسحل انتقال السكان من المناطق الداخلية من أجل التمركز على الشريط الساحلي، وهي ظاهرة تعرفها السواحل المغربية على الأقل منذ النصف الثاني من القرن العشرين، لكنها تبدو اليوم أكثر حدة في السواحل الجنوبية. ويعود هذا لتوفر عدة عوامل محلية منها : - ظروف مناخية أقل قساوة من المجالات الداخلية، مما يجعلها مفضلة للاستقرار البشري. - توفر الموارد السمكية على الساحل. - إمكانيات التواصل والتبادل مع الخارج عبر البحر •

كل ذلك يجعل التركز الديمغرافي مرتفعًا في المجالات الساحلية الصحراوية، بحيث أصبح يتعدى المعدل الوطني بكثير ، إذ يتواجد حوالى 80\% من سكان الأقاليم الجنوبية ضمن المدن الساحلية سنة 2010، وهي نسبة مرتفعة مقارنة بالمعدل الوطني الذي يصل إلى حدود 55\% في الفترة نفسها(7).

وقد أدت ظاهرة التسحل إلى نمو سريع في المدن الساحلية الصحراوية، وقد سجلت أهم التطورات بمدينة العيون، بحيث انتقل تعداد السكان من 103784 نسمة سنة 1982، إلى 1982 نس 253000 نسمة سنة 2013 وفق إحصاء 2014. وتضم مدينة العيون ما يناهز 60\% من سكان الأقاليم الجنوبية.

\begin{tabular}{|c|c|c|c|c|}
\hline 2013 & 2004 & 1994 & 1982 & (السنوات \\
\hline 24800 & 19392 & 14128 & 93875 & \\
\hline 0 & 0 & 4 & 9909 & حضروي \\
\hline 5000 & 5683 & 4443 & 10378 & 4 \\
\hline
\end{tabular}

الجدول رقم 1 : تطور عدد السكان بمدينة العيون ما بين سنة 1982 و 2013(8)

\section{5}

يعدّ الميناء ذو فائدة اقتصادية كبيرة على مدينة العيون، وهو مجال استقطاب للتجعات البشرية؛ وذلك لما يوفره من عمل ومن موارد الصيد البحري، وهذا ما سمح بتطور سريع لميناء مدينة العيون، على اعتبار أن المدينة مركز جذب على مستوى الأقاليم الجنوبية؛ لما تتوفر عليه من موارد طبيعية متعددة، وتتنوع صادراته ووارداته بين المحروقات والإسمنت والفوسفاط والرمال والملح ومواد الصيد البحري. 
إن بناء رصيف ميناء مدينة العيون بشكله الحالي أدى إلى تغيير دينامية التيارات البحرية الجانبية المتجهة من الشمال نحو الجنوب، وهذا ما نتج عن ذلك أمرين أساسيين:

- أصبح الميناء يشكل حاجزًا أمام التيارات الساحلية الجانبية، وهذا ما أفضى إلى تثكيل مجال ترسيب شمال الميناء وتسمينه وتضخمه Engraissement de plage، بحيث تتراكم به الإرسابات القادمة من الثمال، ومجال إفقار وتعرية بجنوبه، فأصبح الميناء يشكل حاجزًا أمام الحمولة الرملية. - أصبحت التيارات الجانبية تصطدم بالميناء، وتدور حوله La diffraction، وتدخل نسبة هامة من حمولتها لترسبها في حوض الميناء، الثيء الذي يسبب ترملّه، ويعرقل حركية المراكب بداخله، وهذا ما يكلف الدولة مصاريف باهظة في عملية جرف الرمال وإفراغها. وتقدر نسبة الرمال التي تتراكم على الرصيف إلى حوالي 500000 م3(9)، بتكلفة تتراوح ما بين 13 إلى 20 مليون درهم في السنة.

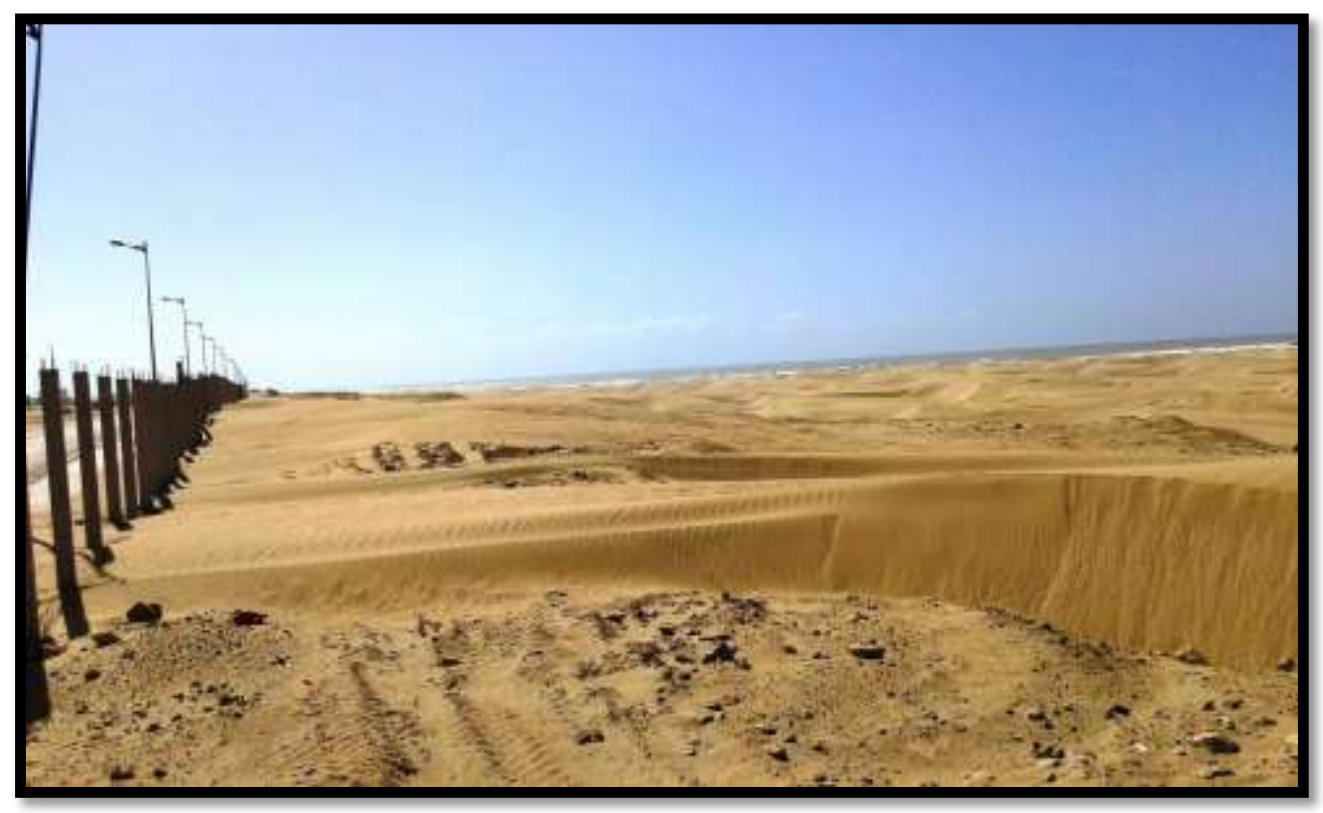

الصورة رقم 1 : توضح مجال الترسيب شمال الميناء الذي شكل فيما بعد كثبان رملية ساحلية بفعل زحف الرمال الذي يميز مدينة العيون. (تصوير شخصي2018)

6

1.6 - وضعية خط الساحل ما بين سنة 1984 و1994:

أ - الثريط الساحلي لجماعة فم الواد: عرف ساحل جماعة فم الواد تحولًا مورفولوجيًا مغايرًا للفترة السابقة، ويتجلى ذلك في أن خط الساحل قد عرف استقرارًا في بعض المجالات، وتقدمًا في عموم ساحل جماعة فم الواد، بحيث تقدم خط الساحل عند الجماعة ب 28 مترًا. أما جنوبها فقد تقدم ب 54 مترًا، وذلك راجع إلى مورفولوجية الثاطئ الرملي المقوسة التي تساعد على حجز الإرسابات القادمة من شمال ساحل جماعة فم الواد بواسطة التيارات الجانبية 
ومما ساعد أيضا على تسمين ساحل مدينة العيون بهذه الفترة الفيضانات التي شهدها الساحل قبل بناء ”سد المسيرة" سنة 1995، هذا عامل، أما العامل الثاني في مسار واد الساقية الحمراء الذي يمر بالحزام أو الوادي الرملي قبل أن يصل للمصب؛ لذا فإن الواد يحمل معه كمية من الرمال في طريقه لمصب فم الواد.

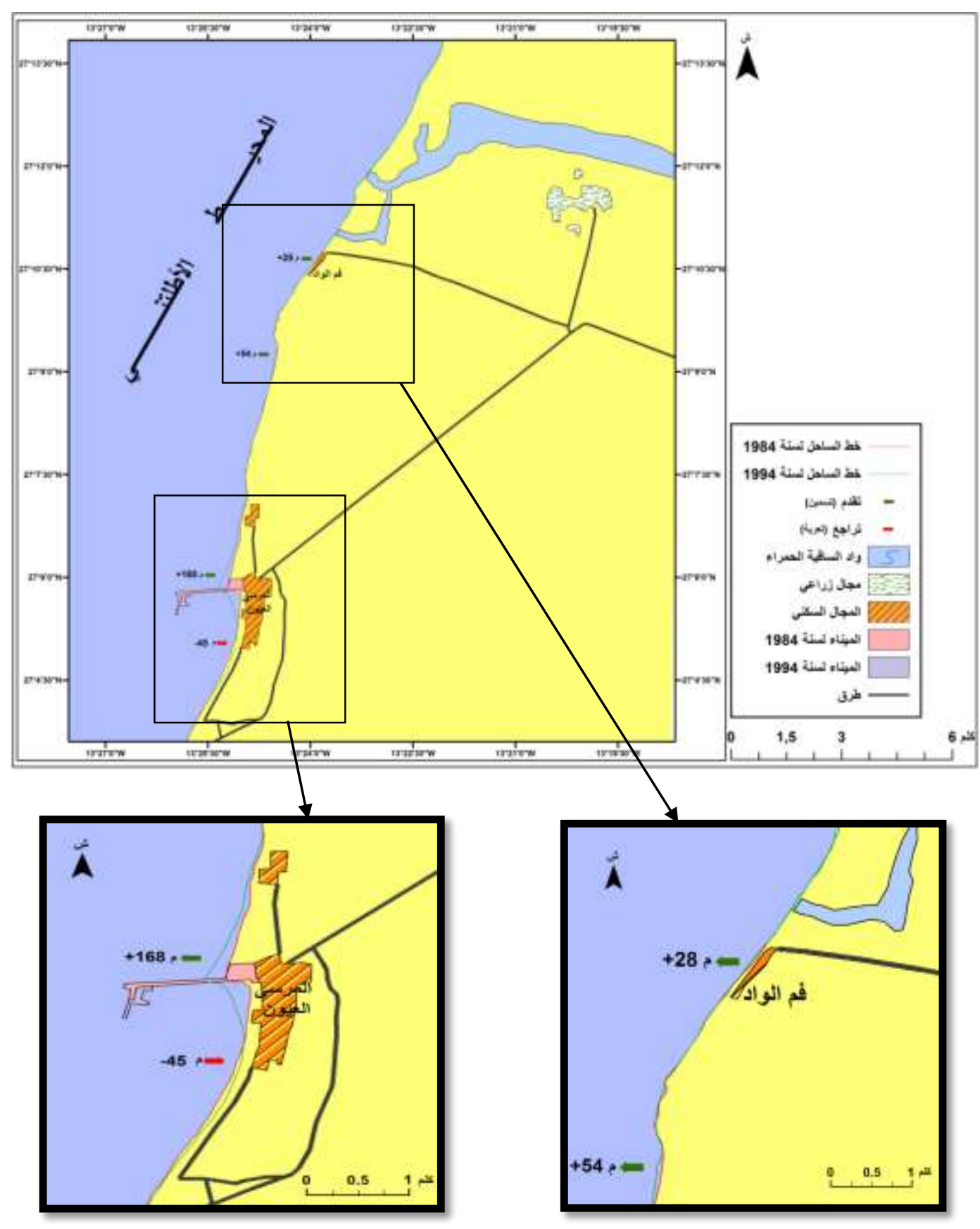

الخريطة رقم 8 : تطور خط الساحل ما بين سنة 1984 و 1994

ب - الشريط الساحلي لمركز المرسى PLAYA : عرف هذا المجال الساحلي تحولًا مورفولوجيًا هو الآخر ، ويتضح ذلك جليًا شمال الميناء وجنوبه، بحيث تقدم خط الساحل ب 168 مترًا شمال الميناء، في حين تراجع ب 45 متراً جنوب الميناء. ويرجع هذا التقدم إلى عملية التوسعة التي شهدها هذا الأخير، وهذا ما تسبب في حجز الإرسابات التي تتوزع من شمال إلى جنوب ساحل مدينة العيون بفعل التيارات الساحلية الجانبية. 


\section{6 - وضعية خط الساحل ما بين سنة 1994 و2005 :}

تميزت هذه الفترة بيناء سد المسيرة سنة 1995، وقد كان لبنائه آثار سلبية على المنظومة الطبيعية، وذلك

بحجزه للحمولة الصلبة التي تأتي بها مياه الفيضانات.

أ - الثربط الساحلي لجماعة فم الواد : عرف ساحل جماعة فم الواد في هذه الفترة تراجعًا واضحًا، لاسيما بجنوب الجماعة، حيث تراجع خط الساحل من الثاطئ الرملي 50 مترًا، في حين تراجع أمام جماعة فم الواد 7 أمتار . ب - الثربط الساحلي لمركز المرسى PLAYA : تقدم خط الساحل شمال الميناء 89 متراً، وتراجع من جنوبه 42 متار . والملاحظ في هذه الفترة كذلك أن خط الساحل تقدم شمال الميناء بشكل ملحوظ مقارنة بالفترة السابقة، ويمكن تفسيره بما ميز هذه الفترة، ألا وهو بناء سد المسيرة، الذي كان لبنائه آثارًا سلبية على تطور خط الساحل بمدينة العيون، بفعل حجزه للحمولة الرسابية التي كان يأتي بها واد الساقية الحمراء خلال فترة الفيضانات.

\section{6 - وضعية خط الساحل ما بين سنة 2005 و2016 :}

شهدت هذه الفترة أقوى فيضان شهده واد الساقية الحمراء منذ سنة 1942، وذلك خلال سنة 2016 بصبيب وصل إلى 3000 متر مكعب/الثانية(10)، هذا ما أدى إلى سقوط سد المسيرة، مما سمح بعبور مياه الفيضان كاملة، والإرسابات التي يأتي بها واد الساقية الحمراء.

أ- الثربط الساحلي لجماعة فم الواد : شهذ مصب فم الواد تحولًا مورفولوجيًا على مستوى شكل المصب، وذلك بسبب كمية المياه الكبيرة التي عبرت الذراع الرملي، ووصلت إلى الساحل، وقد وصل التراجع أمام الجماعة إلى 22 متراً، وبجنوب الجماعة عند الثاطئ الرملي إلى 34 متراً.

ب - الشربط الساحلي لمركز المرسى PLAYA : عرف ساحل مركز المرسى في هذه الفترة تقدمًا لخط الساحل بثمال الميناء 62 مترًا، وإفقار جنوبه وتراجعه 28 مترًا؛ وسبب التراجع الواضح في جنوب الميناء بفعل التوسعة التي عرفها الميناء. 

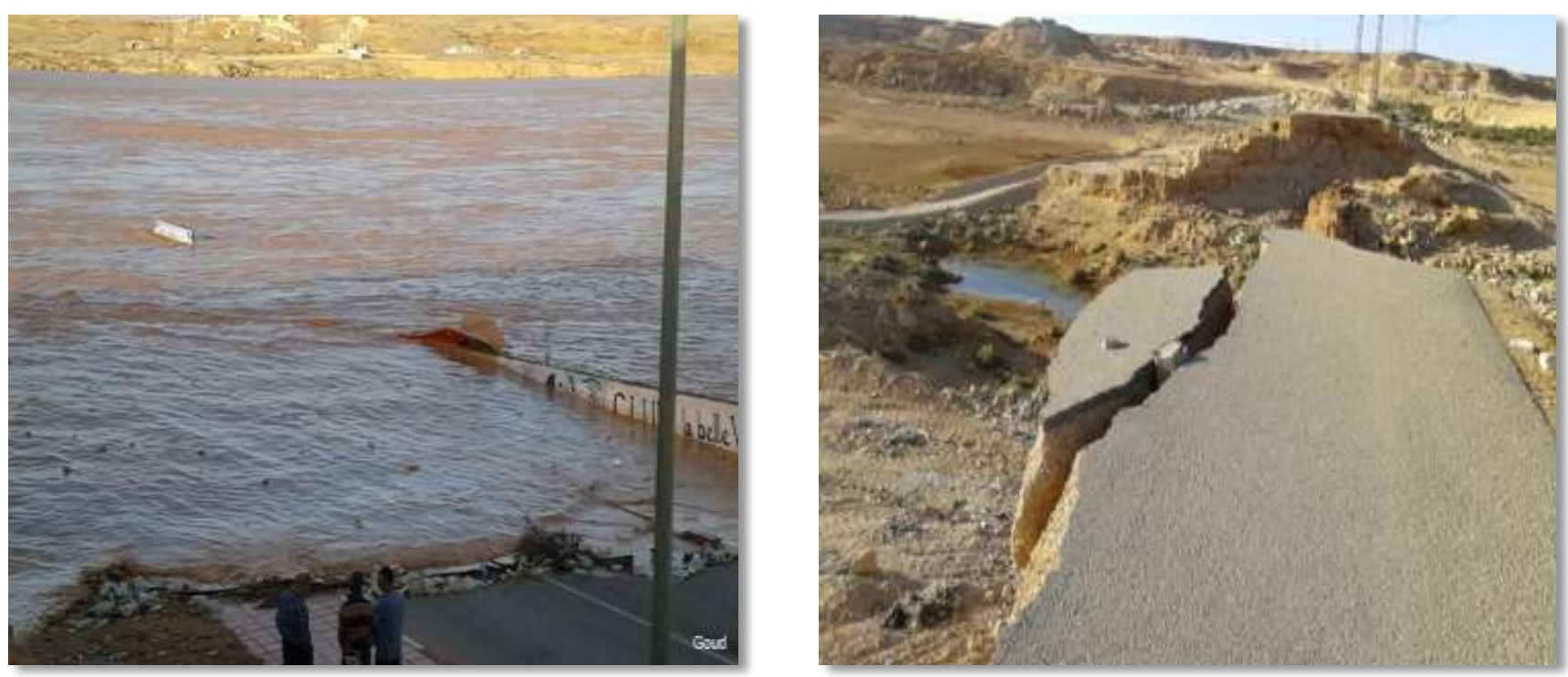

الصورة رقم 2 - 3 : توضحان فيضان الساقية الحمراء الذي دمر سد المسيرة سنة 2016(11) 


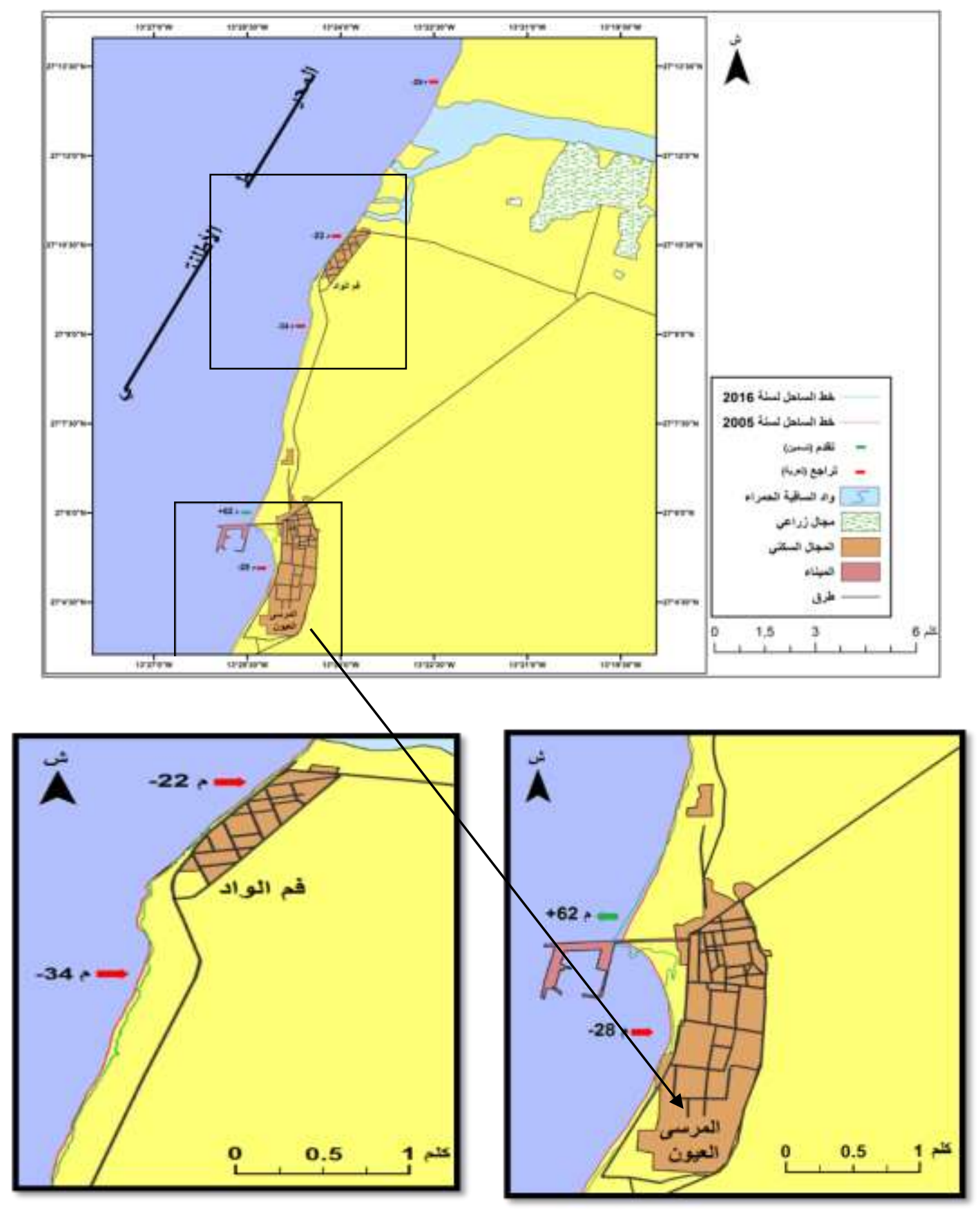

الخريطة رقم 9 : نطور خط الساحل ما بين سنة 2005 و2016 


\section{7 - العوامل الهيدروينامية المؤثرة على خط الساحل في مدينة العيون، والأثكال المورفولوجية الناتجة}

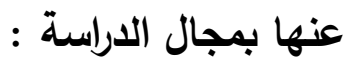

إن التوزيع المرفولوجي للأجراف الصخرية والثواطئ الرملية الضيقة والواسعة بساحل مدينة العيون ما هو إلا نتيجة للعوامل الهيدرودينامية التي تعمل بصفة مباشرة ومستمرة في تقدم أو تراجع لخط الساحل في مجال

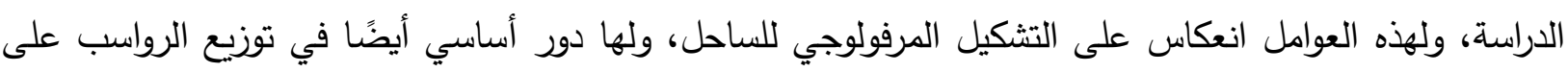

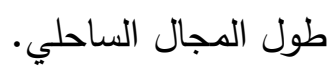

les vagues 1.7 - الأمواجّ من العوامل الهيدرودينامية الأكثر تأثيرًا على الوسط الساحلي، فهي تتميز

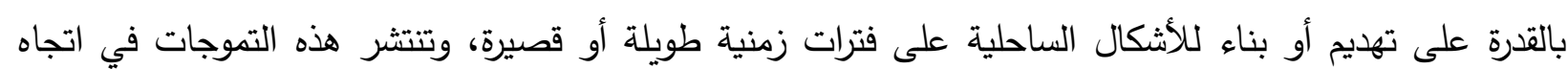

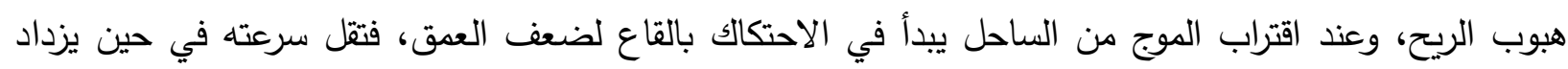
ارتفاعه لينتهي متكسرًا على الساحل (12).

وأهم ما يميز ساحل جماعة فم الواد بالقرب من مصب واد الساقية الحمراء هو رصيف أو مسطحة البري

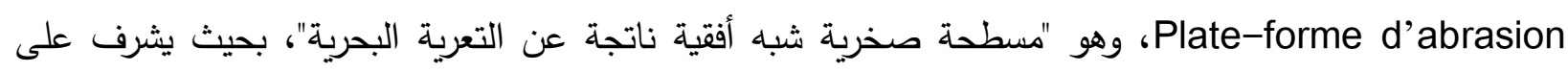
البحر بواسطة جرف حي، "يتثكل من رواسب لوماشيلية رصيصية تعلو مستوى البحر الحالي 2 مترين.
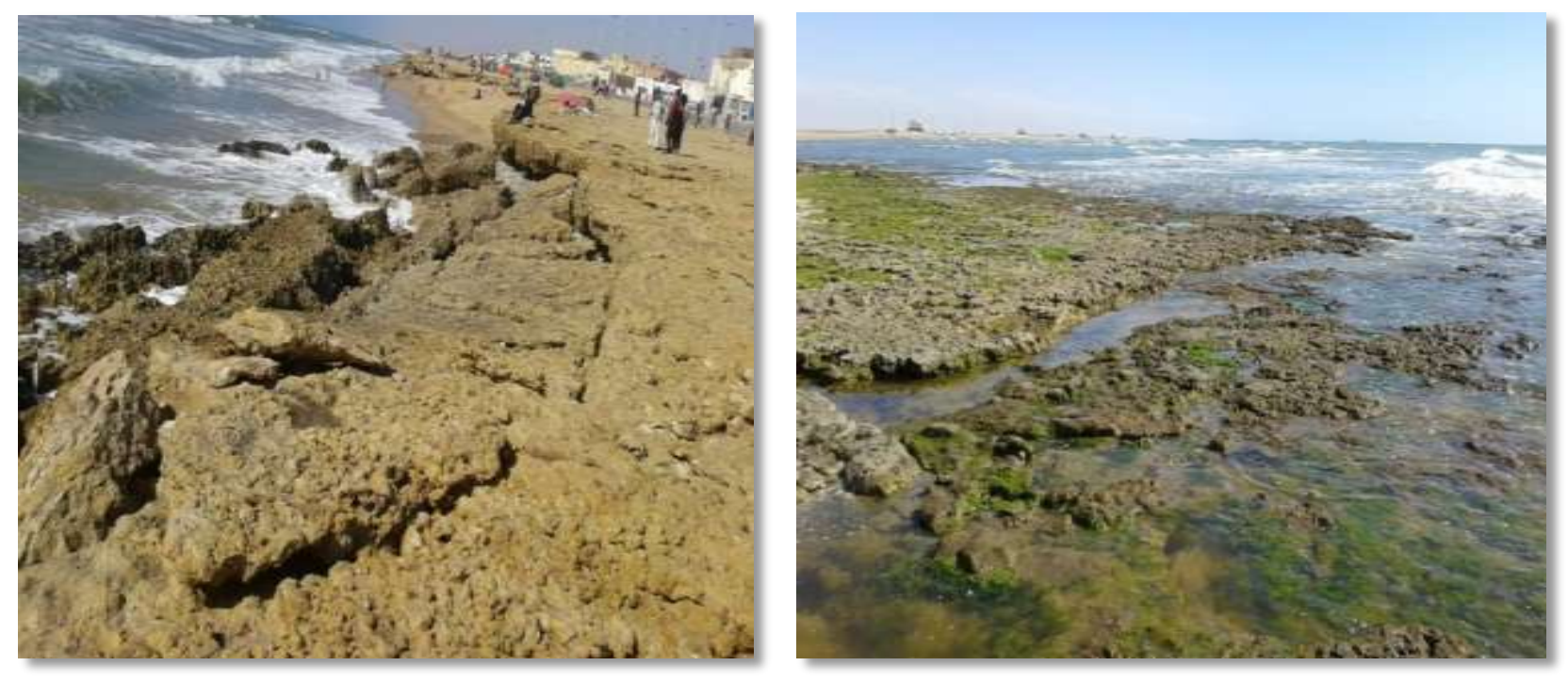

الصورة رقم 4 و 5 : توضحان دور الأمواج الرئيسي في تراجع

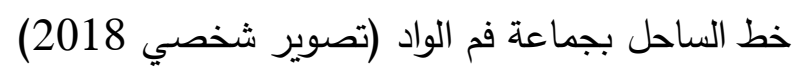



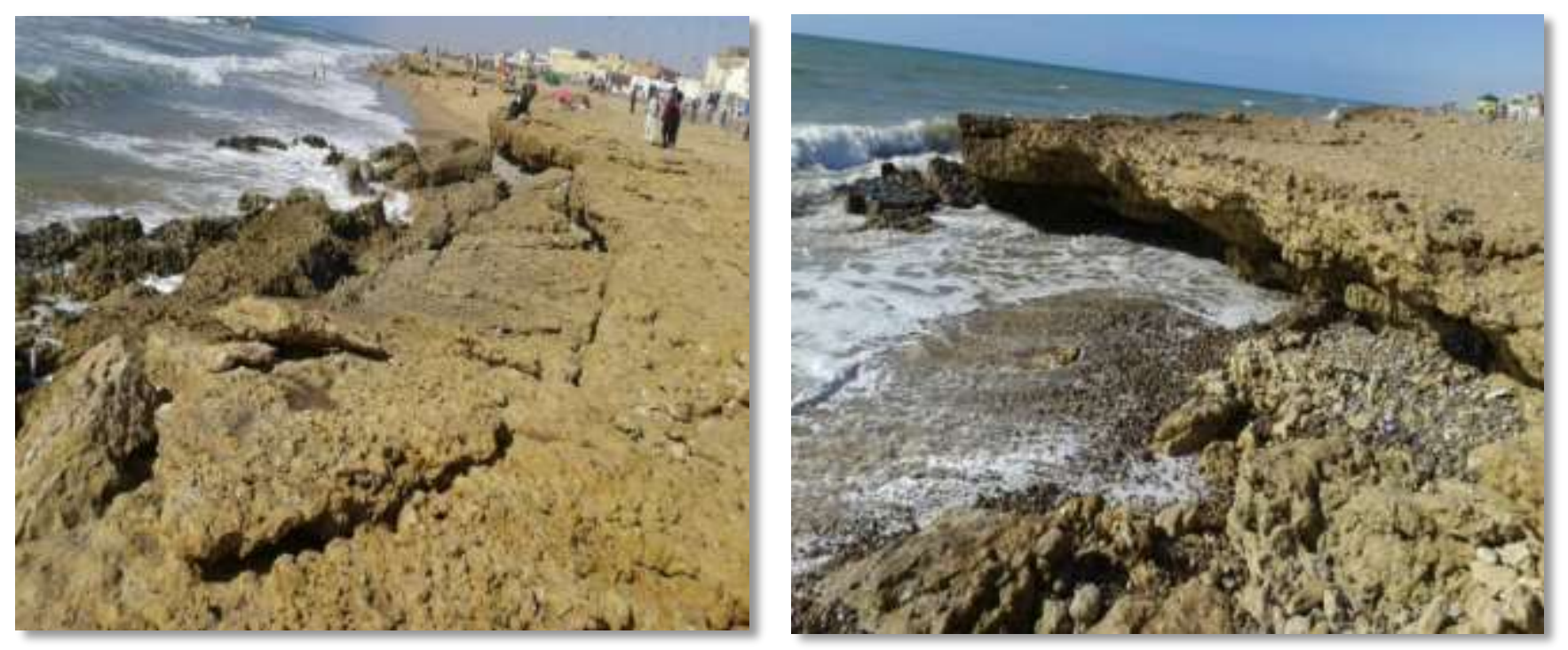

الصور رقم 6-7 : تبين دور الأمواج في تراجع خط الساحل بجماعة فم الواد والأشكال الناتجة عنها (تصوير شخصي 2018)

2.7 - التيارات الفتاتية أو التيارات المائية الساحلية les dérives littoral : تعد هذه التيارات من أهم العوامل La zone de التي تساهم في انتقال المواد على مستوى الساحل، فهي تحدث في منطقة تكسر الأمواج déferlement هذه التيارات اتجاهها في ساحل العيون من الثمال نحو الجنوب (الثكل رقم 1 بتصرف، ROLAND .(PASKOFF, Impact des aménagements sur leur évolution فالتيارات الساحلية أو الفتاتية حساسة جداً أمام التخخلات البشرية التي تقام على الساحل، مثل الموانئ والبناءات الحضرية والساحلية، وهذا يؤدي إلى تحولات في دينامية التيارات الساحلية من حيث الاتجاه والسرعة، تؤدي إلى حدوث اضطرابات في مواقع التعرية والتسمين. فبناء ميناء مدينة العيون داخل البحر أدى إلى تغيير دينامية التيارات المتجهة من الثمال نحو الجنوب، مما نتج عنه مشكلتين أساسيتين : علعاءهاء

الأولى : أصبح شمال الميناء مجال ترسيب، تتراكم فيه الإرسابات التي تأتي بها التيارات الساحلية من الثمال. والثانية: ترمل الميناء بفعل التيارات الساحلية، غعندما تصطدم برصيف الميناء تدور حوله متسببة في دخول الرمال إلى حوض الميناء فترمله. 


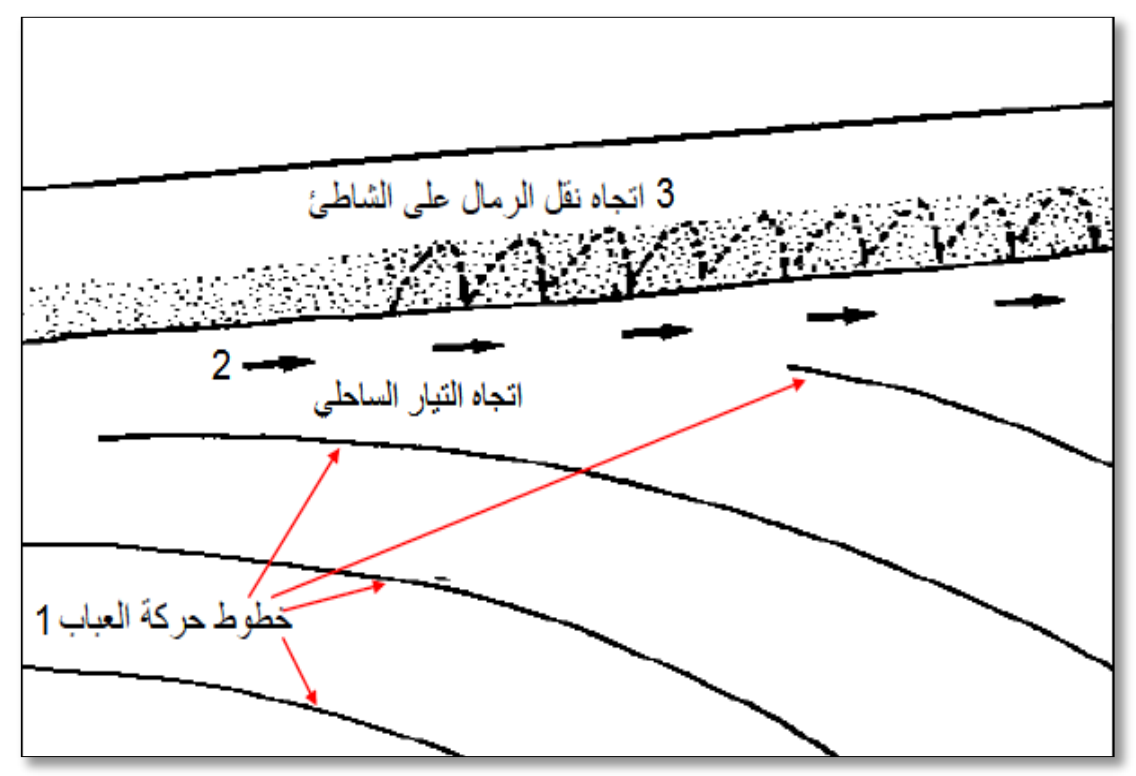

الثكل رقم 1 : يوضح طريقة تنقل الرمال بواسطة التيارات الفتاتية، بتصرف(13)

3.7 - تيار التراجع Courant de retrait : تيار التراجع هو تلك الكتل المائية التي تصطدم بالساحل، وفي أثناء رجوعها عن طريق الجاذبية إلى عرض البحر ينتج عنها تيار قوي، يسمى تيار الرجع، هذه التيارات تنشأ في منطقة تكسر الأمواج، وسرعتها ترتبط ارتباطًا وثيقًا بكمية الطاقة التي تحررها الأمواج، وترتبط كذلك بانحدار الثاطئ، فكلما كان انحدار الشاطئ شديدًا كانت كمية المواد المنقولة نحو البحر كبيرة.

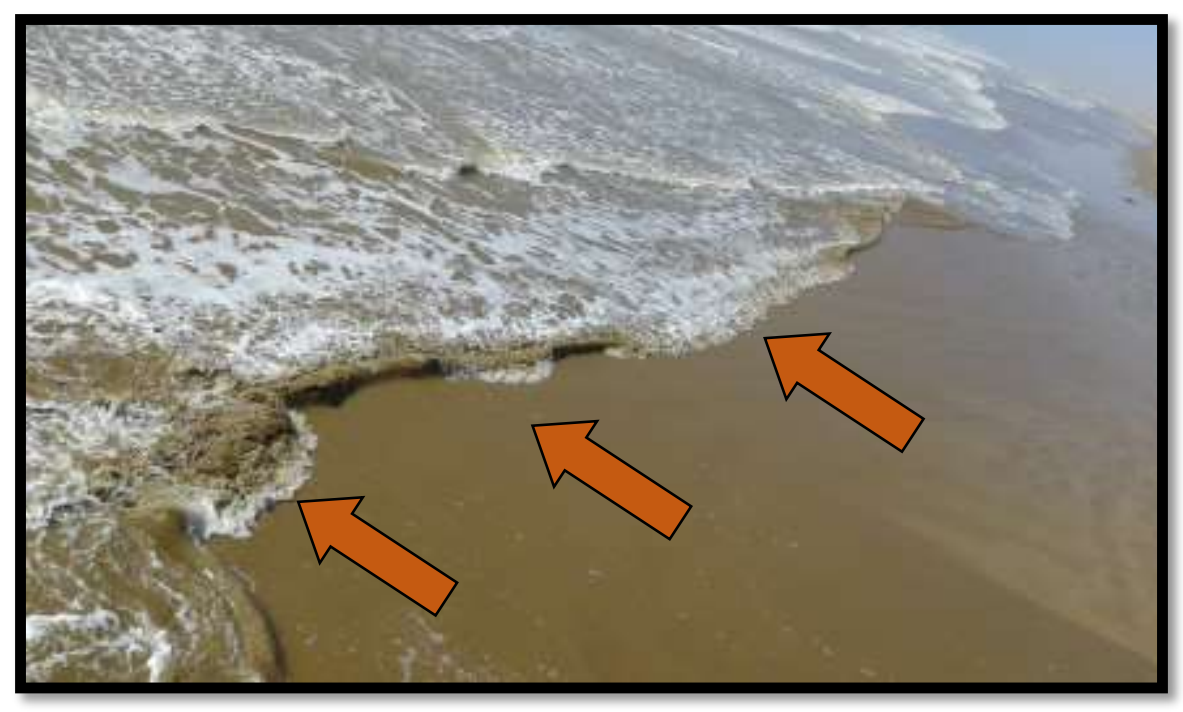

الصورة رقم 8 : توضح كيفية عمل تيار التراجع في نقل الرمال نحو البحر بالثاطئ الرملي شمال ميناء العيون (تصوير شخصي 2018) 


\section{8}

\section{8 - تقنيات الحماية البحرية المتوضعة على خط الساحل :}

تتوضع هذه التقنيات مباشرة على خط الساحل، وهدفها الرئيس هو حماية الهنشآت البشرية من خطر التعرية

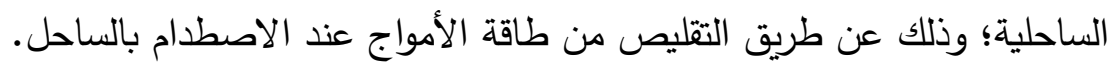

الدعامة الساحلية / الحاجز الساحلي les digues : الدال

الحاجز الساحلي هو منثأة موازية لخط الساحل، يستعمل لحماية شتّى المنشآت الساحلية، ويوجد هذا النوع من

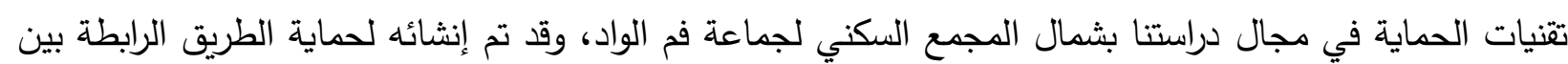

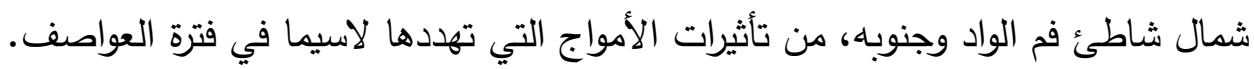

\section{الصخور الخرسانية الاصطناعية Les Enrochements :}

تُّعد هذه التقنية أحد أنواع الحواجز الساحلية Les Digues وذلك بوصفها من أكثر الحواجز استعمالًا على المستوى

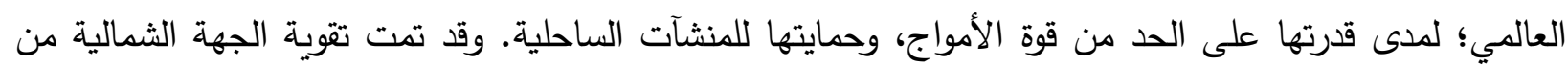
ميناء مدينة العيون سنة 1987 بصخور خرسانية اصطناعية؛ وذلك لحماية الواجهة الثمالية من الميناء من تأثيرات الأمواج ذات اتجاه الثمال الغربي.
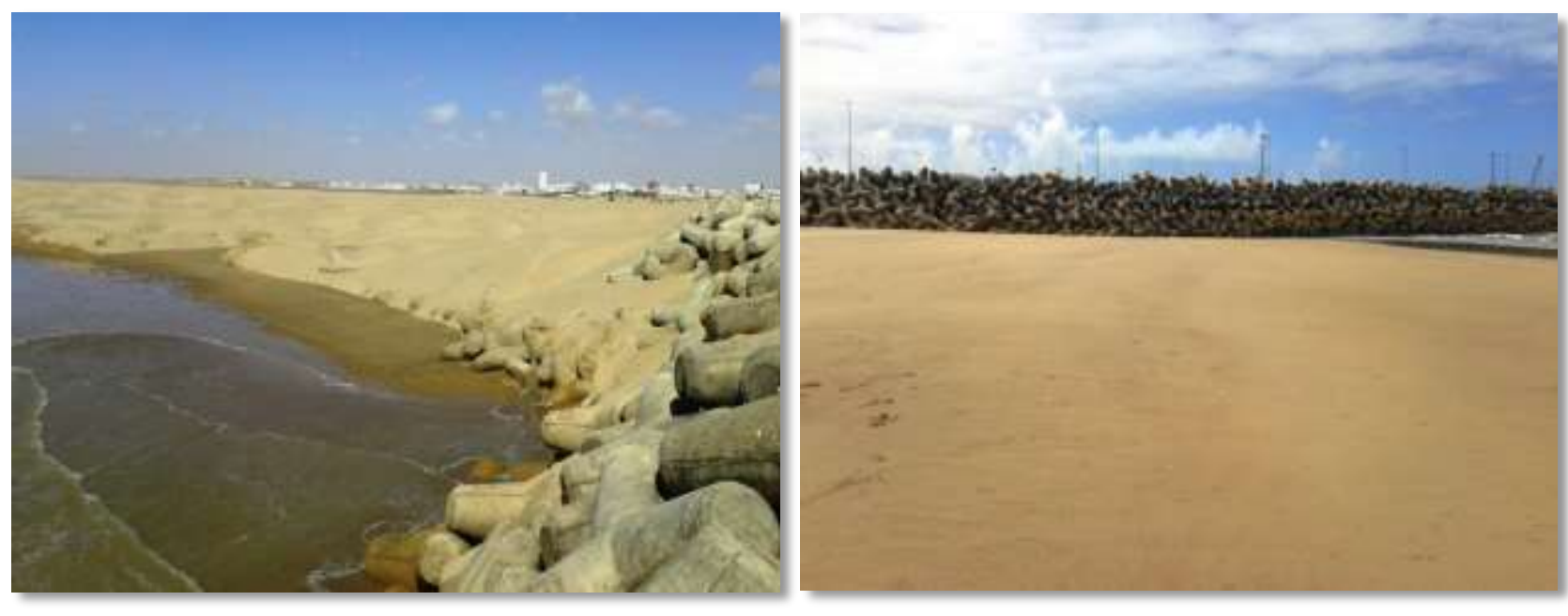

الصور رقم 9 - 10 : الصخور الخرسانية الاصطناعية بالواجهة الثمالية ليناء العيون(تصوير شخصي 2018) 


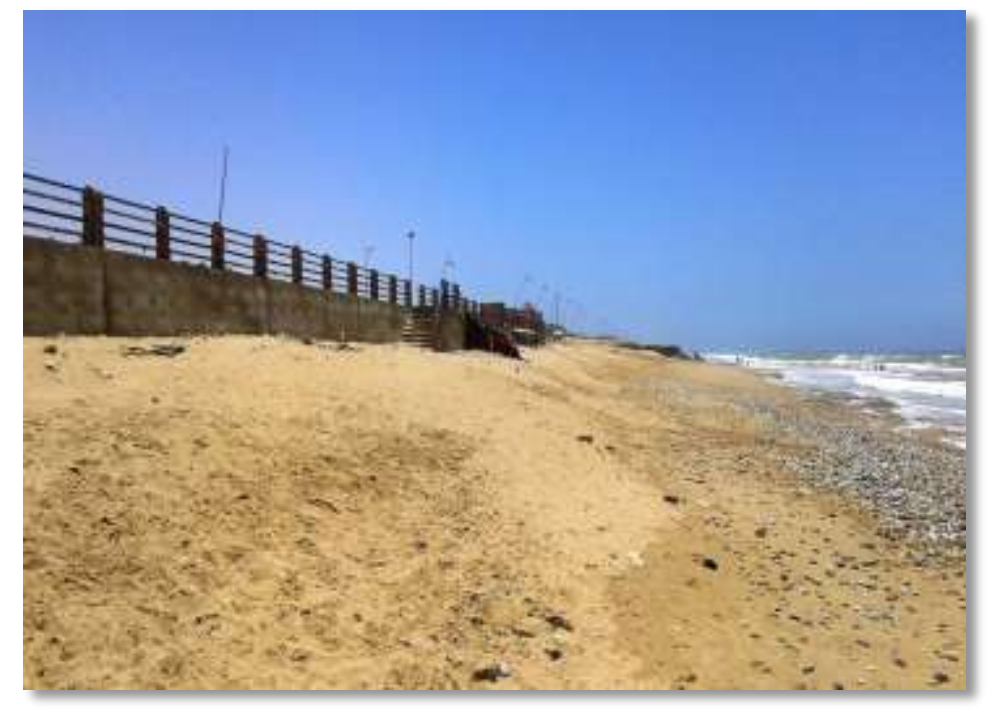

الصورة رقم 11 : الحاجز الساحلي المتواجد بشمال المجمع السكني لفم الواد (تصوير شخصي 2018) 2.8 - آفاق التدخلات التقنية بساحل مدينة العيون :

قام مكتب الدراسات ARTELIA MAROC بإنجاز دراسة لحماية الساحل الجنوبي لساحل فم الواد، وتم التوصل للحل الأمثل لحماية هذا المجال، ويتمثل هذا الحل في FRONT DE MER، يتم إنجازه على طول 362 متر في الثطر الأول من المشروع، ويتراوح طول الساحل الجنوبي المراد حمايته 1600 متر مشروعاً عاماً. وانطلقت الأشغال مع بداية سنة 2019، بمدة أشغال تصل إلى 11 شهرًا، بتكلفة تقدر بـ 48 مليون درهم.

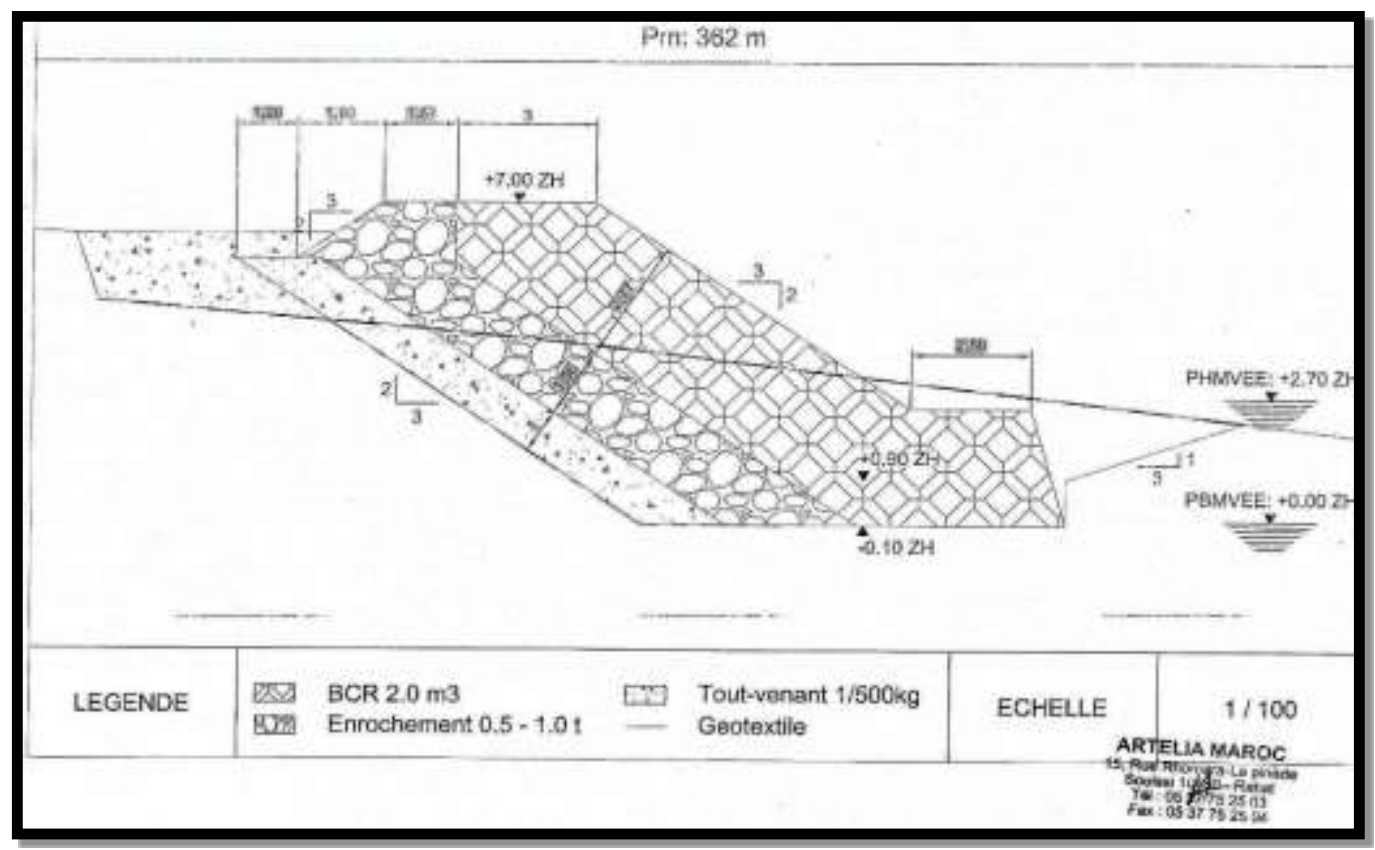

الثكل رقم 2 : مقطع يوضح المميزات الهندسية ومكونات بناء Front de mer في الساحل الجنوبي لشاطئ فم الواد المقترحة من مكتب الدراسات ARTELIA MAROC : 


\section{الخاتمة}

يثكل ساحل مدينة العيون وسطًا هشًا ناتجاً عن تظافر عدة عوامل طبيعية وبشرية، فالهجال الساحلي هو نظام قائم

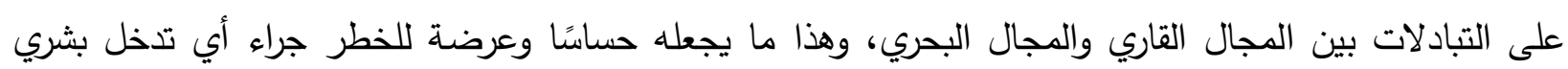

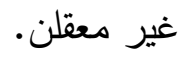

ولقد قمنا بهذه الدراسة قصد التعريف بهذا الوسط الساحلي الصحراوي المتمثل في ساحل إقليم العيون، للثريط الساحلي الواقع بين مصب واد الساقية الحمراء ومركز المرسى.

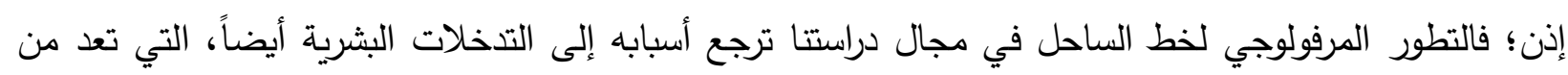

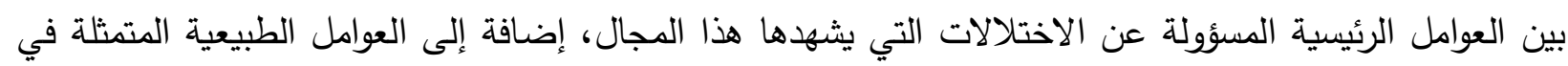

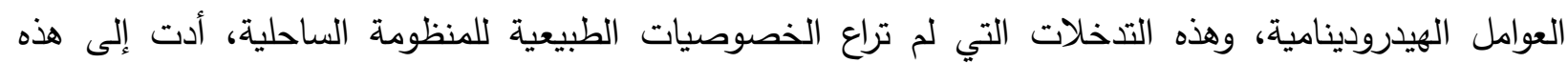

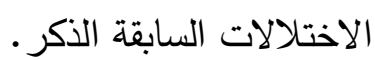

وفي ظل كل هذه الاختلالات نلاحظ القصور الكبير الذي يُطال التببير الساحلي بمدينة العيون، حيث أن كل

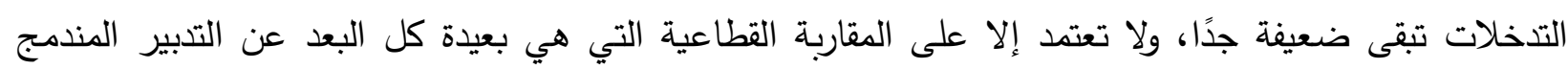
للدجالات الساحلية، وستزيد من التدهور الذي شههه الوسط الساحلي. فالتتخلات التتنية التي ستقام على ساحل

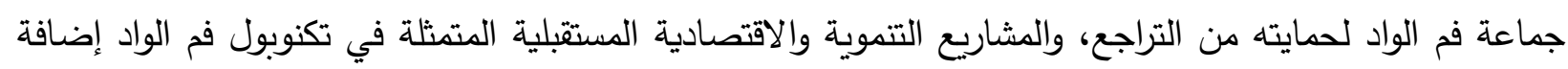
إلى الفنادق، كلها ستزيد من حدة التطورات السلبية على مستوى الخط الساحلي لددينة العيون.

ومن هذا المنطلق يجب تفعيل قانون الساحل المغربي على أرض الميدان؛ لاستصلاح المنظومة الساحلية

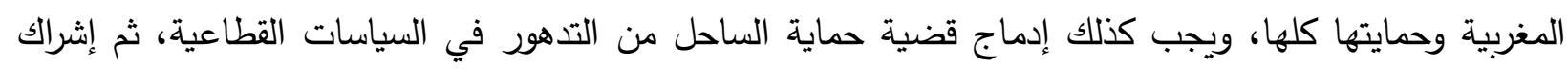

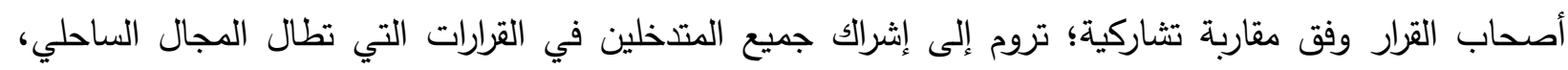
وبهذا يمكن ضمان تدبير مندمج ومستدام للنظام الساحلي. 
المصادر والمراجع

• جمال خلوق، 2009، التدبير الترابي بالمغرب واقع الحال ومطلب التنمية، الطبعة الأولى.

زينب مبسوط، 2018، الإنسان والماء في الصحراء المغربية الأطلنتية، الطبعة الأولى.

• عبدالرحيم وطفة، محمد طيلسان، الميلود شاكر، عبدالرحيم بنعلي، الطبعة الأولى 2006، الأقاليم الجنوبية المغربية

" البيئة والمجتمع وآفاق التنمية.

عبدالعزيز فعراس، الطبعة الأولى أكتوبر 2016، السواحل الجنوبية : مجال ومجتمع، بيئة وتنمية.

• عبدالعزيز فعراس، 2010؛ الماء والتتمية الحضرية في المجال الصحراوي : حالة مدينة العيون الساقية الحمراء،

الطبعة الأولى.

فتيحة موفق، 2012، معجم جغرافية البحر ( فرنسي - عربي ).الطبعة الأولى.

محمد منسوم، 2015، الجيومورفلوجية العامة مدخل إلى علم التضاري، الطبعة الأولى.

واحمان إبراهيم، 2007، الجنوب المغربي : الخصائص الجيولوجية والبنيوية الصحراء الأطلنتية : المجال والإنسان. منشورات وكالة الجنوب. الرباط.

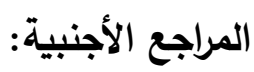

- ARTELIA MAROC, 2017, Etude de protection contre l'érosion du littoral de foum el oued.

- MANSOUM MOHAMED, octobre 2016, les littoraux marocains : changement climatique et stratégie de gestion, paysage géographiques $\mathrm{N}: 2$.

- MANSOUM MOHAMED, les différents impact croisés entre littoraux et bassin versant dans les régions arides et semi-arides les cas d'Essaouira, Eau et enjeux du développement durable, avril 2012.

- MANSOUM MOHAMED, La cartographie prospective de l'évolution du littoral d'Essaouira, publication de la faculté des lettres et des sciences humaines sais-Fès $\mathrm{N}: 25$.

- ROLAND PASKOFF, 1985, Impact des aménagements sur leur évolution. 